\title{
A generic framework for e-commerce requirements to comply with Sharia in business- to-consumer perspective
}

\begin{abstract}
The serious concern over fulfillment of the essential requirements of Sharia by the conventional e-commerce system constitutes a barrier to e-commerce adoption and use among many Muslims. Therefore, it is important to explore and understand the essential requirements for Sharia compliant e-commerce specifically in Business to Consumer (B2C) setting. Our research has identified the necessary requirements for e-commerce Sharia compliant. The requirements are categorised into two; Islamic law of contract, and Sharia prohibition in e-commerce. The requirements for Islamic law of contract those include compliant with form (offer and acceptance), contracting parties (buyer and seller), and subject matter (object and price). In addition, the requirements for prohibition in e-commerce are referred to the avoidance of fundamentally prohibited elements of riba, gharar, haram and maysir. Furthermore, we have developed a generic framework of requirements for B2C Sharia compliant e-commerce. This framework will serve as a guide to consumers in determining the legitimacy of an e-commerce transaction in the light of Sharia. Besides, ecommerce merchants, web application developers and other stakeholders will gain clear understanding of these requirements to improve the development and diffusion of Sharia compliant e-commerce application. Conclusively, this research postulates that, any ecommerce transaction or platform that complies with the Islamic law of contract and is devoid of any fundamentally prohibited element (riba, gharar, haram and maysir) is deemed Sharia compliant.
\end{abstract}

Keyword: E-commerce; Islamic law of contract; Sharia compliant; Sharia requirement 